\title{
TINJAUAN TENTANG KETERKAITAN PARAMETER DENGAN MODEL REGRESI MULTIVARIAT PADA KOLAM IKAN TERTUTUP
}

\author{
R. Sudrajat ${ }^{1}$, Dwi Susanti ${ }^{1}$ \\ ${ }^{1)}$ Departemen Ilmu Komputer FMIPA Universitas Padjadjaran Bandung \\ ${ }^{2)}$ Departemen Matematika FMIPA Universitas Padjadjaran Bandung \\ r.sudrajat@unpad.ac.id,dwi.susanti@unpad.ac.id
}

\begin{abstract}
ABSTRAK
Penelitian ini bertujuan untuk mendeskripsikan model regresi ekosistem kolam untuk kolam ikan tertutup (Recirculating Aquaculture System disingkat RAS). Kajian model ini membahas tentang variable-variabel dan parameter yang utama dapat mempengaruhi keberlangsungan ekosistem kolam sehingga dapat menggambarkan transformasi materi dalam ekosistem. Model ini memberikan kemudahan dalam memilih proporsi optimal untuk menggambarkan keterkaitan antar variabel dan parameter untuk perairan kolam agar dapat mengoptimalkan lahan. Variabel yang diamati dalam percobaan yang dilakukan selama 92 hari adalah : Luas Media Pengurai Amoniak ( Spesific Surface Area), Volume Air, Luas Kolam, Suhu, PH, Jumlah Amoniak terlarut, dan Oksigen Terlarut (Dissolved Oxygen). Kajian awal dalam penelitian ini dilakukan uji regresi untuk melihat pengaruh antar variable dan parameter. Dari hasil pengamatan dan kajian regresi terlihat bahwa pengaruh luas media sangat dominan terhadap keberlangsungan ekosistem kolam
\end{abstract}

Keywords : Model Regresi, Spesific Surface Area, Amoniak

\section{PENDAHULUAN}

Perkembangan teknologi informasi telah mengalami kemajuan yang sangat pesat diantaranya adalah teknologi pengambilan keputusan untuk sebuah model, serta memberikan andil besar terhadap perubahan-perubahan yang mendasar pada struktur pengelolaan suatu objek kajian. Dengan teknologi informasi berbagai analisis juga dapat dikembangkan dalam mendukung sistem informasi untuk meningkatkan efektifitas kinerja suatu objek kajian sehingga dapat menentukan efektifitas dan efisiensi. Objek kajian yang akan diteliti dalam sanitasi lingkungan perairan kolam tertutup adalah merupakan bahan yang akan diteliti. Kualitas air dalam kolam tertutup sangat dipengaruhi oleh parameter baik fisika, kimia maupun biologi, antara lain : suhu, amoniak, nitrogen, ph, oksigen terlarut, zat padat dan nutrisi-nutrisi. (Physicochemical Parameters of Natural Waters. Portland, Stevens Water Monitoring Systems, Inc.: 17 hlm. Deekae, S.N., J.F.N. Abowei \& A.C. Chindah. 2010)

Secara spesifik, masalah yang menjadi fokus utama penelitian ini adalah model prototipe kolam dan media pengurai dalam ekosistem kolam dibangun untuk kolam tertutup (Recirculating Aquaculture System disingkat RAS). 


\section{Eksakta Vol. 18 No. 2 Oktober 2017}

\section{METODE PENELITIAN}

Metode Penelitian yang dilakukan adalah :

1. Kajian Literatur

2. Menentukan media pengurai amoniak (filter biologi) yang akan dirancang.

3. Membuat kajian model regresi dan korelasi untuk melihat pengaruh antar variable dan parameter

4. Studi kasus menggunakan prototipe kolam sederhana dengan media porositas

sesuai kebutuhan riset.

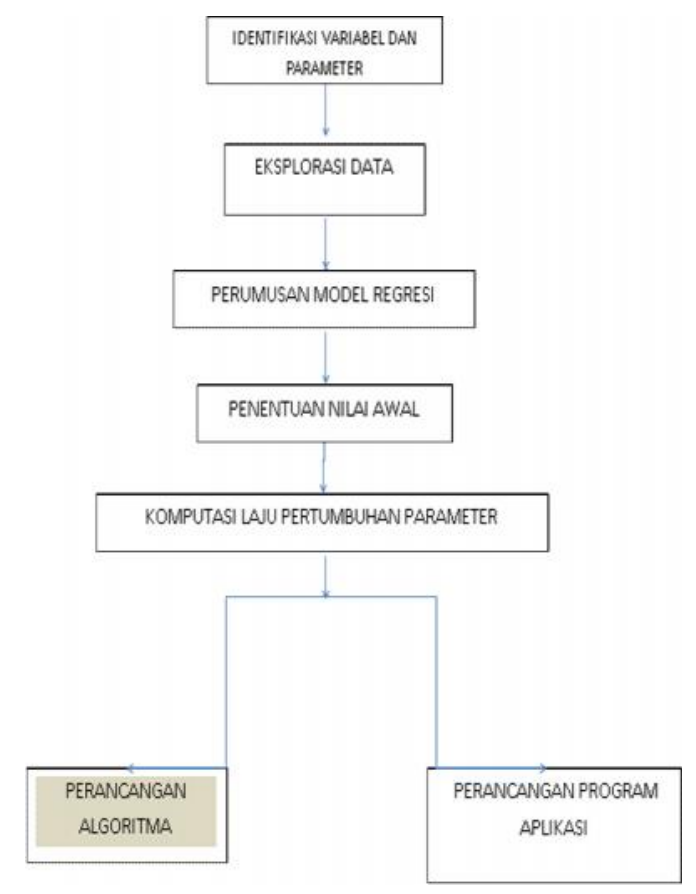

Gambar 1 : Langkah Skema Penelitian yang sedang dirancang

\section{E-ISSN : 2549-7464, P-ISSN : 1411-3724}

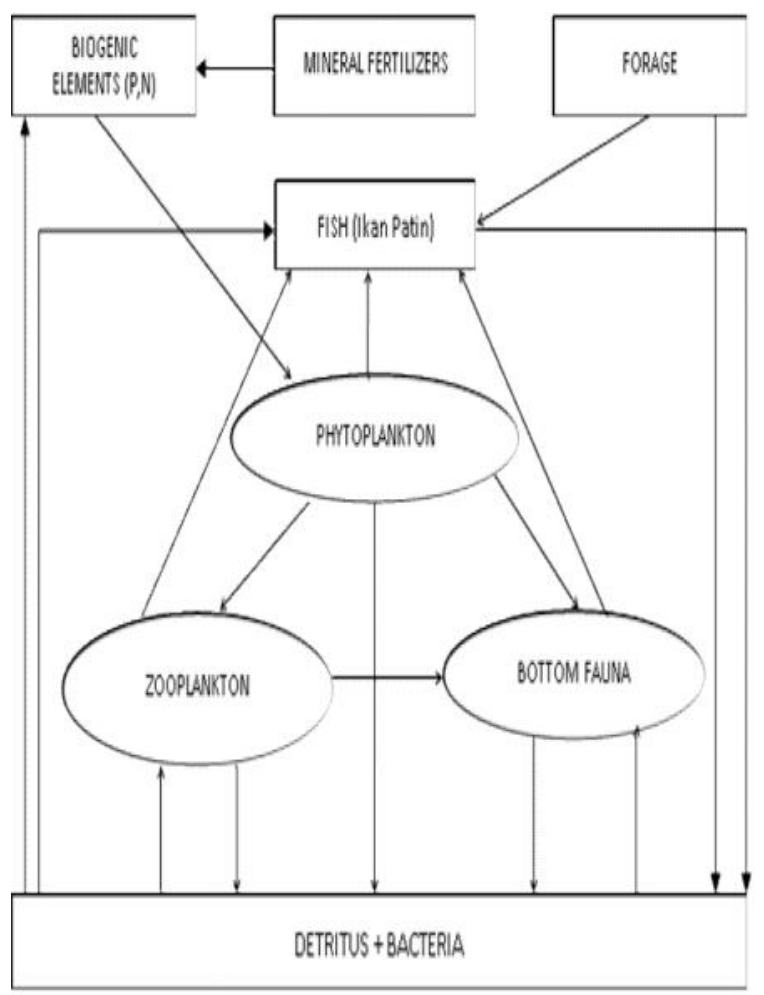

Gambar 1. Siklus Material dalam ekosistem kolam ikan

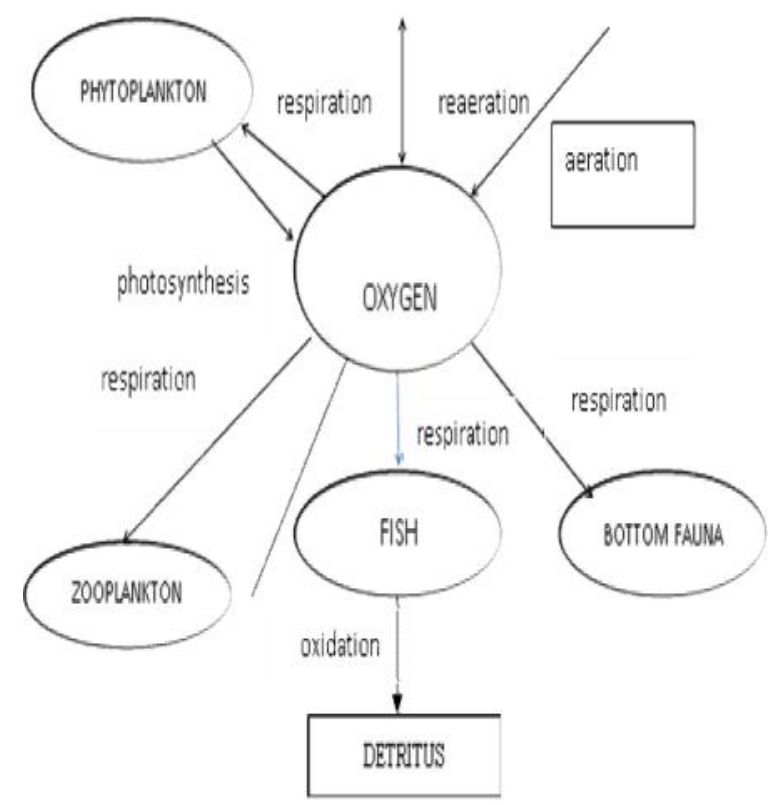

Gambar 3. Inflows dan Outflows Oxygen dalam ekosistem kolam ikan 
E-ISSN : 2549-7464, P-ISSN : 1411-3724

\section{HASIL PENELITIAN DAN PEMBAHASAN \\ Hasil Penelitian}

Hasil yang dicapai pada tahap awal penelitian sesuai dengan rancangan adalah :

1. Rancangan dan Spesifikasi Kolam Kolam dibuat persegi panjang

2. Luas Kolam

- Luas kolam pemeliharaan ikan 1,6 meter $\mathrm{x} 3,6 \mathrm{~m}=5,76 \mathrm{~m}^{2}$

- Luas Kolam Filter $3 \mathrm{~m}^{2}$

- Luas Media Filter (SSA= Spesific Surface Area) $=300 \mathrm{~m}^{2}$

3. Volume Air

- Kedalaman Kolam Pemeliharaan $=0,75 \mathrm{~m}$

- Volume air kolam pemeliharaan $1,6 \mathrm{~m} \times 3,6 \mathrm{~m} \times 0,75 \mathrm{~m}=4,60 \mathrm{~m}^{3}$

- Volume air media filter $=1,4 \mathrm{~m}^{3}$

- Volume air keseluruhan kolam $=6 \mathrm{~m}^{3}$

4. Peralatan kolam

- Pompa sirkulasi merk Resun 230 watt

- Pompa udara (Air Pump) merk resun 60 watt

- 3 buah batu gelembung $7 \mathrm{~cm}$

- Slang gelembung udara $10 \mathrm{~m}$

- Tekanan pompa 1 liter per detik

Metoda pengambilan data dilakukan setiap hari dengan pengamatan langsung pada lokasi eksperimen (data primer) selama 92 hari. Data digunakan untuk mencari korelasinya. Korelasi ini menggunakan metoda Regresi Linier Multivariat dengan sistem persamaan linier yang terbentuk diselesaikan menggunakan dekomposisi matriks LU.

\section{Pembahasan}

\section{Regresi Linier Multivariat}

Banyak data pengamatan dapat terjadi karena pengaruh lebih dari dua variabel. Dalam penelitian ini ditentukan hubunngan antara variabel terikat $y$ dengan variabel bebas x1, x2, x3, ..., xk sehingga didapat regresi y atas x1, x2, x3, ...., xk, garis regresi ini disebut Regresi Linier Multivariat.

Model persamaan Regresi Linier Multivariat y terhadap x1, x2, x3, ..., xk adalah

$$
=\mathrm{a} 0+\mathrm{a} 1 * x 1+\mathrm{a} 2 * x 2+\mathrm{a} 3 * x 3+\ldots+\mathrm{ak} * \mathrm{xk},
$$

dengan a0, a1, a2, a3, ...., ak sebagai koefisien-koefisien yang harus ditentukan dari data.

Kasus pada pengamatan ini ada empat variabel bebas $\mathrm{x} 1, \mathrm{x} 2, \mathrm{x} 3, \mathrm{x} 4$ sehingga regresi linier multivariat adalah

$$
=\mathrm{a} 0+\mathrm{a} 1 * x 1+\mathrm{a} 2 * x 2+\mathrm{a} 3 * x 3+\mathrm{a} 4 * x 4,
$$

dengan a0, a1, a2, a3, dan a4 ditentukan dari sistem persamaan linier:

$\sum y=a_{0} n+a_{1} \sum x_{1}+a_{2} \sum x_{2}+a_{3} \sum x_{3}+a_{4} \sum x_{4}$
$\sum y x_{1}=a_{0} \sum x_{1}+a_{1} \sum x_{1}^{2}+a_{2} \sum x_{1} x_{2}+a_{3} \sum x_{1} x_{3}+a_{4} \sum x_{1} x_{4}$
$\sum y x_{2}=a_{0} \sum x_{2}+a_{1} \sum x_{1} x_{2}+a_{2} \sum x_{2}^{2}+a_{3} \sum x_{2} x_{3}+a_{4} \sum x_{2} x_{4}$
$\sum y x_{3}=a_{0} \sum x_{3}+a_{1} \sum x_{1} x_{3}+a_{2} \sum x_{2} x_{3}+a_{3} \sum x_{3}^{2}+a_{4} \sum x_{3} x_{4}$
$\sum y x_{4}=a_{0} \sum x_{4}+a_{1} \sum x_{1} x_{4}+a_{2} \sum x_{2} x_{4}+a_{3} \sum x_{3} x_{4}+a_{4} \sum x_{4}^{2}$

dengan $\mathrm{y}=$ Jumlah Pakan Ons/hari, $\mathrm{x} 1=$ Kadar Keasaman (PH), $\mathrm{x} 2=$ Suhu (Celsius), $\mathrm{x} 3$ = Amoniak mg/liter, dan $\mathrm{x} 4$ $=$ Oksigen $(\mathrm{DO})$.

Nilai a0, a1, a2, a3, dan a4 koefisienkoefisien yang akan ditentukan.

Kesalahan standar taksiran ditentukan menggunakan

$$
s_{y .123 \ldots k}^{2}=\frac{\sum\left(y-y^{*}\right)^{2}}{n-(k+1)}
$$
formula 


\section{Eksakta Vol. 18 No. 2 Oktober 2017}

E-ISSN : 2549-7464, P-ISSN : 1411-3724

dengan $\mathrm{y}^{*}$ adalah nilai taksiran dari fungsi regresi.

\section{Dekomposisi Matriks}

Matriks A5x5 sebagai berikut

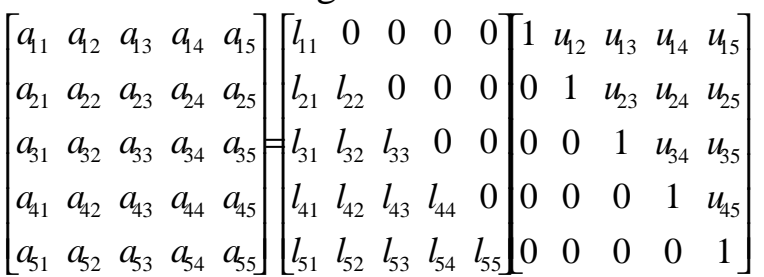

\begin{tabular}{|c|l|l|l|l|l|l|l|}
\hline 4 & 4 & Juni & 7.83 & 26.5 & 0.45 & 7.3 & 10 \\
\hline 5 & 5 & Juni & 7.73 & 26.5 & 0.55 & 7.2 & 10 \\
\hline 6 & 6 & Juni & 7.75 & 27 & 0.55 & 7.4 & 10 \\
\hline 7 & 7 & Juni & 7.7 & 26.5 & 0.55 & 7.7 & 10 \\
\hline 8 & 8 & Juni & 7.71 & 26 & 0.55 & 6.7 & 7.5 \\
\hline 9 & 9 & Juni & 7.7 & 26 & 0.45 & 6.5 & 7.5 \\
\hline 10 & 10 & Juni & 7.75 & 26 & 0.45 & 6.5 & 7.5 \\
\hline 11 & 11 & Juni & 7.69 & 27 & 0.45 & 6.4 & 7.5 \\
\hline 12 & 12 & Juni & 7.66 & 26.5 & 0.45 & 6.4 & 7.5 \\
\hline
\end{tabular}

Untuk medekomposisi menjadi matriks LU dilakukan dengan mengikuti langkahlangkah berikut.

Langkah 1: Mencari nilai elemen-elemen dari matriks $\mathrm{L}$ dan matriks $\mathrm{U}$

$$
\begin{aligned}
l_{\mathrm{i1}} & =a_{i 1} \\
u_{1 \mathrm{j}} & =a_{1 \mathrm{j}} / l_{11}=a_{1 \mathrm{j}} / a_{11} \\
l_{\mathrm{ij}} & =a_{\mathrm{ij}}-\sum_{k=1}^{j-1} l_{i k} \cdot u_{k j} \\
u_{\mathrm{ij}} & =\frac{a_{i j}-\sum_{k=1}^{i-1} l_{i k} \cdot u_{k j}}{l_{i i}}, \text { dengan } \mathrm{i}=1,2,3, \ldots,
\end{aligned}
$$

$\mathrm{n}$ dan $\mathrm{j}=2,3,4, \ldots, \mathrm{n}$.

Langkah 2 : mencari vektor matriks hasil ( $\left.\mathrm{H}^{\prime}\right)$ dengan membuat augmented LH dan perhitungan

$$
\mathrm{h}_{1}{ }_{1}=\mathrm{h}_{1} / l_{11} \quad \mathrm{~h}^{\prime}=\frac{h_{i}-\sum_{k=1}^{i-1} l_{i k} \cdot h_{k}^{\prime}}{l_{i i}}
$$

Langkah 3 : membentuk augmented matriks UH' dan mencari solusi dengan aturan

$$
x_{\mathrm{n}}=\mathrm{h}_{\mathrm{n}} \quad x_{\mathrm{j}}=\mathrm{h}_{\mathrm{j}}-\sum_{k=j+1}^{n} u_{j k} \cdot x_{k}
$$

Tabel 1 : Tabel Instan Data Pengamatan

\begin{tabular}{|l|l|l|l|l|l|l|l|}
\hline $\begin{array}{l}\text { No } \\
\cdot\end{array}$ & Tgl & $\begin{array}{l}\text { Bulan } \\
\text { Th(20 } \\
\mathbf{1 7 )}\end{array}$ & $\begin{array}{l}\text { PH } \\
\mathbf{x 1}\end{array}$ & $\begin{array}{l}\text { Suh } \\
\mathbf{u} \\
\mathbf{( C )} \\
\mathbf{x 2}\end{array}$ & $\begin{array}{l}\text { Amo } \\
\text { niak } \\
\mathbf{m g} / \mathbf{l i} \\
\mathbf{t e r} \\
\mathbf{x 3}\end{array}$ & $\begin{array}{l}\text { DO } \\
\mathbf{( O k} \\
\text { sige } \\
\mathbf{n}) \\
\mathbf{x 4}\end{array}$ & $\begin{array}{l}\text { Pak } \\
\mathbf{a n} \\
\mathbf{O n} \\
\mathbf{s} / \mathbf{h} \\
\mathbf{a r i} \\
\mathbf{y}\end{array}$ \\
\hline 1 & 1 & Juni & 8.43 & 27 & 0.45 & 8.9 & 10 \\
\hline 2 & 2 & Juni & 7.81 & 27 & 0.45 & 8.1 & 10 \\
\hline 3 & 3 & Juni & 7.84 & 27 & 0.45 & 7.5 & 10 \\
\hline
\end{tabular}

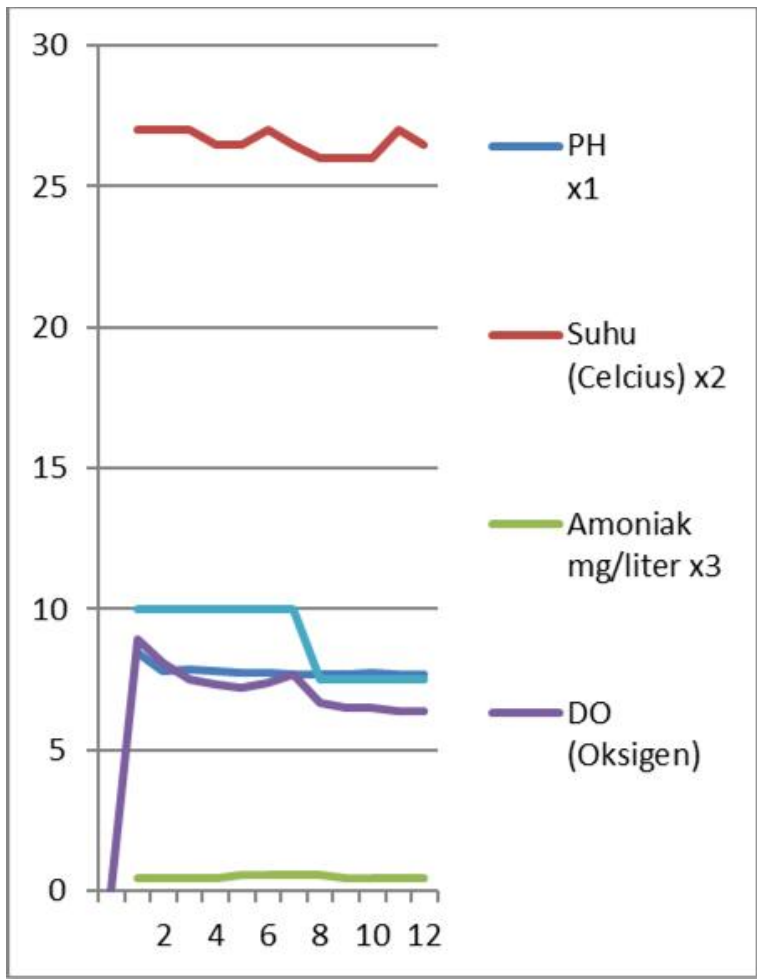

Gambar 4 : Grafik data hasil pengamatan

Dari data pengamatan diperoleh nilainilai:

$\Sigma x_{1}=680,65, \Sigma x_{2}=2413,5, \Sigma x_{3}=42,2$,

$\Sigma \mathrm{x}_{4}=2413,5, \Sigma \mathrm{y}=434,0$. 


\section{Eksakta Vol. 18 No. 2 Oktober 2017}

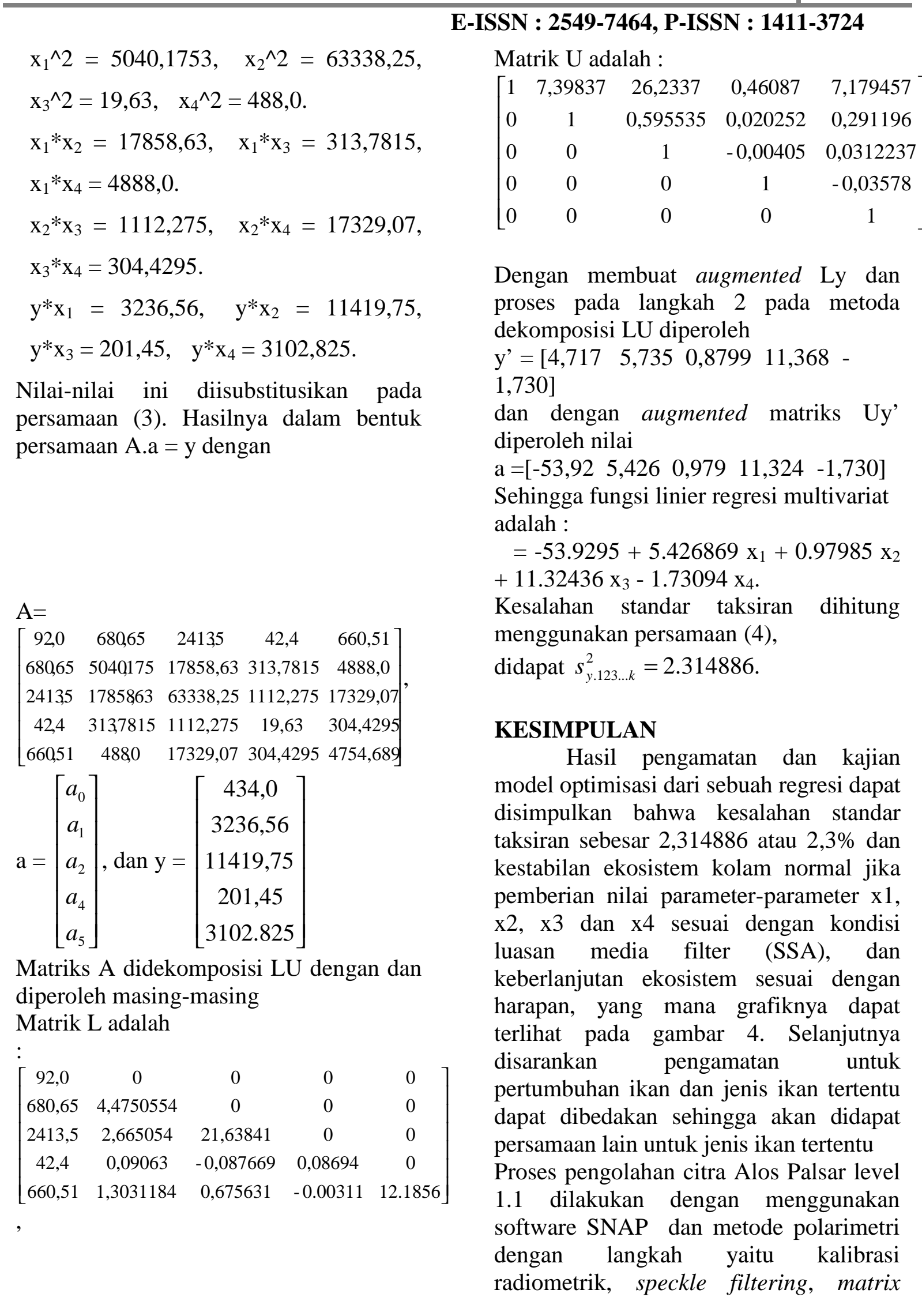


generation, dan yamaguchi decomposition serta koreksi geometrik. Berdasarkan hasil klasifikasi citra ALOS PALSAR level 1.1 menggunakan metode polarimetri, citra yang dihasilkan mampu mengklasifikasi objek dengan modifikasi penyederhanaan kelas. Kelas yang dihasilkan yaitu kelas pemukiman, vegetasi, dan badan air.

\section{DAFTAR PUSTAKA}

[1] Deekae, S.N., J.F.N. Abowei \& A.C. Chindah, "Physicochemical Parameters of Natural Waters. Portland, Stevens Water Monitoring Systems, Inc.: 17 hlm. 2010

[2] Matt Smith " Sizing a Biofilter" Published by L. S. Enterprises, PO Box 13925, Gainesville, FL 32604 USA 2013

[3] Onada, Olawale.Ahmed, Akinwole,A.O, Ajani Emmanuel.Kolawole, " Study of Interrelationship Among Water Quality Parameters in Earthen Pond and Concrete Tank", Department of Aquacultureand Fisheries, University of Ibadan, 2015

[4] Sudjana, Prof. Dr. M.A, M.Sc. “

Teknik Analisis Regresi dan Korelasi Bagi Para Peneliti”

[5] Torsten E.I. Wik a,, Björn T. Lindén , Per I. Wramner, Integrated dynamic aquaculture and wastewater treatment modeling for recirculating aquaculture systems, journal homepage: www.elsevier.com/locate/aqua-on line, Aquaculture 287 (2009) 361-370 